\title{
RESEARCH ON CHANGE AND GROWTH OF STUDENTS AND TEACHERS EXPERIENCED PROBLEM BASED LEARNING
}

\author{
Kyungwon Chang and Seonyoung Jang \\ Kyonggi University, Mokpo National Maritime University, South Korea
}

\begin{abstract}
The purpose of this study is to identify change and growth of students and teachers experienced PBL. For this purpose, this study used both quantitative and qualitative approach to examine the impact of PBL and the change and growth of students and teachers. 2,970 students and 172 teachers participated in this study. The results of the students' change and growth based on students' answer to a survey and interview are as follow; first, the satisfaction of PBL class has statistically increased at the end of term than the beginning of the term. Second, PBL have the effects on improving students' self-efficacy. Third, based-on students' interview, it was identified that a good class and a PBL have common points in communication, cooperation and cooperation among learners, knowledge acquisition and understanding of contents. Forth, students experienced PBL had enhanced their skills in five areas; solving problem, cooperation, communication, academic motivation, and human relations. The results of the teachers' change and growth are as follows; first, teachers realized the importance of PBL higher than before, and had the volition to do the PBL consistently. Second, the teachers' efficacy has improved at a significant level. Third, teachers recognized that the characteristics of PBL classes were full of energy, not boring, and students are able to lead the class, understand learning contents, and focus on the class and a good class was similar to PBL. Forth, teachers experienced PBL have acquired the knowledge (property of PBL/property of students), behavior (confidence of PBL class), and techniques (designing PBL class, PBL tutoring) at a level 1(level of PBL implementation). In addition, they have figured out the necessary of extension of PBL (school organization, teacher community; researching) at a level 2.
\end{abstract}

\section{KEYWORDS}

Problem-Based Learning, Growth of Students and Teachers, Quantitative and Qualitative Approach

\section{THE PURPOSE OF THIS STUDY}

Problem-based learning (PBL) is a teaching and learning method in which students learned learning contents and skills during solving authentic problem (Barrows \& Myers, 1993). Many studies reported that students improved their skills of problem solving, communication, interpersonal relationship, and learning deepen knowledges by PBL. Also, the teachers' efficiency on teaching also enhanced through PBL. However, those researches have the limits of presenting their specific stories. The purpose of this study is to identify that how students and teachers who experienced PBL are changed and grown.

\section{THEORETICAL BACKGROUND}

PBL is the teaching-learning method of suggesting the learning experience to the students with the authentic problems (Barrows \& Myers, 1993). The main features of PBL are as follows. First, the learning starts from the problem. In PBL, the learning experience starts from the activities for solving the suggested problem. Therefore, solving problems in PBL is comprehensive activities including the learning issues. Authentic, ill-structured problems are used to recognize the appropriateness of the learning which can experience in real world (Dunlap, 2005). Second is the learning environment focused on learners. PBL is held with the activities by learners, not through teacher-led lecture (Barrows, 1996). Thus, learners have the responsibility to their learning by themselves. Third, PBL learning is based on the group activities. Problem solving process in PBL 
is held by group activities. Furthermore, personal learning is held during the group activities. Fourth, learners study the new knowledges through self-directed learning. Thus, PBL requires not only group activities, but also self-directed learning.

The effectiveness of PBL suggested by precedent researches is focused on the aspects of learners' content knowledge, academic motivation, problem-solving ability, cooperative ability and communication skills (Barron et al., 1998; Grant, 2011; Krajcik et al., 1994). Moreover, some studies suggested the effectiveness of PBL on teachers who held PBL classes. Following are the details.

First is the effects on the aspect of students. To check the effectiveness of PBL, other major techniques are teamwork, cooperation, problem solving skills, motivation, communication skills (speaking and writing), content knowledge, collecting information, expert knowledge and techniques, data analysis, critical thinking, project management, self-efficacy, and time management. To synthesize, learners got the content knowledge (Barron et al., 1998; Geier et al., 2008; Mergendoller et al., 2007; Walker \& Leary, 2009), academic motivation (Belland et al., 2006; Brush and Save, 2008), and learning capability for 21st century (Krajcik et al., 1994; Markham et al., 2003: Belland et al., 2006; Blumenfeld et al., 1991; Grant, 2011; Mergendoller et al., 2006) through the experience of PBL.

Second is the effectiveness in the aspect of teacher. PBL class requires considerable preparation and different running strategies compared to previous classes to teachers. Therefore, it will bring the noticeable change not only to students, but also to teachers. However, most studies are focused on the change of students who experienced PBL classes, so it is difficult to find the researches about the effectiveness on teachers of the PBL. Nevertheless, through the several researches introduced, PBL has increased the level of knowledge of teachers about the teaching materials, capability related to PBL; problem development, running capability, and self-efficacy (Finkelstein et al., 2010; Goodnough \& Hung, 2009; Tawfik, Trueman, \& Lorz, 2013).

\section{RESEARCH METHODS}

This study was conducted on five middle school students and teachers designated as PBL research schools in Daegu, South Korea. Daegu City has designated schools for PBL practice as part of its project to implement and expand PBL. Five schools in 2017 were designated PBL research schools. Students and teachers of five designated middle schools in 2017 were participated in this study.

Specific research procedures are as follows. First, the researchers have conducted the workshop and consulting for teachers to understand PBL and design PBL class. The PBL classes were implemented from September to December on 2017 in five middle schools. During this period, both quantitative and qualitative studies were conducted to identify student and teacher growth and change through PBL experience.

Quantitative research was conducted as follows. We surveyed at the beginning and the end of the semester to identify changes in students and teachers. A questionnaire for students' self-efficacy developed by Kim and Kim (2004) was adopted in this study. This questionnaire is consisted of demographic variables (sex, age, school, and grade), PBL satisfaction, and self-efficacy. 2,970 students responded to the questionnaire. Questionnaire for teachers developed by Kim and Park (2001) was adopted in this study. The questionnaire was consisted of demographic variables (gender, age, school, career experience, charge subject, grade in charge) and teachers' efficacy. 172 teachers responded to the questionnaire. The results of students and teachers' responses were analyzed using SPSS 24.

Qualitative research was done as follows. We interviewed students and teachers to understand their change and growth. In the interview, 43 students were asked about the characteristics of good class, the perception of PBL, the experience of PBL team activities, problem solving process, outcomes of PBL, and the role of teachers in PBL. Interviews were conducted at 5 schools, and 3-4 students were interviewed at each grade level. We also conducted interviews with teachers. 30 teachers were asked about the characteristics of good classroom teachers, perception of PBL, experience of PBL design and implement, and teachers' role. Interviews with students and teachers were recorded and cross-analyzed by researchers. 


\section{RESULTS}

\subsection{The Change and Growth of Students}

The quantitative and qualitative data collected from students is shown as follows. First, the satisfaction of PBL class has statistically increased at the end of term than the beginning of the term (Table 1). In detail, the satisfaction of team activities in PBL class showed the highest rate of change and the satisfaction of PBL facilitation skill and attitude showed relatively lower rate of change.

Table 1. Comparison in satisfaction of students before and after PBL classes

\begin{tabular}{c|c|c|c|c|c|c|c}
\hline \multirow{2}{*}{ item } & \multicolumn{2}{|c|}{ Pre-test } & \multicolumn{2}{c|}{ Post-test } & \multicolumn{2}{c|}{ difference } & \multirow{2}{*}{ t-value } \\
\cline { 2 - 7 } & $\mathrm{M}$ & $\mathrm{SD}$ & $\mathrm{M}$ & $\mathrm{SD}$ & $\mathrm{M}$ & $\mathrm{SD}$ & \\
\hline Problems in PBL & 3.67 & .981 & 3.84 & .975 & -.176 & 1.341 & $-5.271^{* * *}$ \\
\hline Teacher's facilitation skill and attitude & 3.81 & .916 & 3.94 & .929 & -.128 & 1.271 & $-4.026^{* * *}$ \\
\hline Team activities in PBL & 3.60 & 1.032 & 3.81 & .992 & -.214 & 1.401 & $-6.112^{* * *}$ \\
\hline Evaluation in PBL & 3.70 & .964 & 3.87 & .954 & -.171 & 1.338 & $-5.132^{* * *}$ \\
\hline${ }^{*} P<05,{ }^{* *} P<.01^{* * *} P<.001$ &
\end{tabular}

${ }^{*} P<.05,{ }^{* *} P<.01,{ }^{* * *} P<.001$

Second, PBL have the effects on improving students' self-efficacy $(p<.05)$ (Table2). In particularly, comparison in before and after PBL experience, the factor of task difficulty preferences has increased from 3.54 to 3.25 ( $\mathrm{p}<.001)$, self-regulated efficacy statistically decreased from 3.58 to $3.51(\mathrm{p}<.05)$.

Table 2. Comparison in self-efficacy of students

\begin{tabular}{|c|c|c|c|c|c|c|c|c|}
\hline \multirow{2}{*}{\multicolumn{2}{|c|}{ Variable }} & \multicolumn{2}{|c|}{ Pre-test } & \multicolumn{2}{|c|}{ Post-test } & \multicolumn{2}{|c|}{ Difference } & \multirow{2}{*}{ t-value } \\
\hline & & $\mathrm{M}$ & SD & M & SD & M & SD & \\
\hline & Self-efficacy & 3.42 & .567 & 3.46 & .585 & -.042 & .804 & $-2.098^{*}$ \\
\hline \multirow{3}{*}{$\begin{array}{c}\text { Sub- } \\
\text { Variable }\end{array}$} & Task difficulty preferences & 3.17 & .681 & 3.25 & .681 & -.080 & .951 & $-3.357^{* *}$ \\
\hline & Self-regulation efficacy & 3.54 & .664 & 3.64 & .723 & -.093 & .985 & $-3.762^{* * *}$ \\
\hline & Confidence & 3.58 & .850 & 3.51 & .939 & .068 & 1.260 & $2.157^{*}$ \\
\hline
\end{tabular}

Third, students reported a good class is consisted with the factors such as students' communications, interactions, developments, achievements, interests and attentions. Also, they answered that the significant characteristics of PBL are learner-centered, authentic problems and assignments based, progress of learning, growth and achievements of learning. Based-on students' interview, it was identified that a good class and a PBL have a common point in communication, cooperation and cooperation among learners, knowledge acquisition and understanding of contents.

Fourth, the learners experienced PBL had enhanced their skills in five areas; solving problem, cooperation, communication, academic motivation and human relations. The parts of learners' growth are classified based on cognitive-affective domain and learning-relationship domain. The cognitive domain and the affective domain are the main factor of consisting the human-ability and itis the taxonomy in generic term of mental ability related to gaining and using knowledge. The cognitive domain contains the thinking abilities such as understanding, application, analytical skills, synthesizing, problem-solving, logical thinking, critical thinking, creativity, and evaluation. The affective domain is about human's interests, attitude, admiring, value, emotion and belief. Complex factors as like focusing on some situation and internal coherent personality and conscience are included in the affective domain. It also contains the attention, reaction, acceptance of values, conviction and systematization, internalization, personification of value. Learning is continuous transition of attitude by the results of practice and experiences, and generally, ideal and progressive change is regarded as learning. Relation is the idea of pairing and thinking of the two objects and the relations learners have in school is included the relations with other learners and tutors. According to those criteria, students had made growth through PBL in the aspects of problem solving, communicating, academic motivation, human relations and cooperation because PBL is held with individual and team learning activities. 


\subsection{The Change and Growth of Teachers}

The change and growth of teachers are shown as follows. First, teachers who experienced PBL realized the importance of PBL higher and had the volition to do the PBL consistently as they implement the PBL and checking the results of students (Table 3.).

Table 3. Comparison in teachers' perspective and volition before and after PBL

\begin{tabular}{c|c|c|c|c|c|c|c|c}
\hline \multirow{2}{*}{ items } & \multicolumn{2}{|c|}{ Pre-test } & \multicolumn{2}{c|}{ Post-test } & \multicolumn{2}{c|}{ Difference } & \multirow{2}{*}{ t-value } \\
\cline { 2 - 8 } & $\mathrm{M}$ & $\mathrm{SD}$ & $\mathrm{M}$ & $\mathrm{SD}$ & $\mathrm{M}$ & $\mathrm{SD}$ & & \multirow{2}{*}{-1.727} \\
\hline $\begin{array}{c}\text { PBL is a teaching method to improve } \\
\text { higher order thinking ability }\end{array}$ & 3.88 & .947 & 4.07 & 1.012 & -.188 & 1.282 & & $-2.936^{* *}$ \\
\hline I will implement PBL classes in the future & 3.64 & 1.086 & 3.99 & 1.124 & -.348 & 1.392 & & $-2.092^{*}$ \\
\hline Extension of PBL is necessary & 3.72 & 1.025 & 3.96 & 1.100 & -.239 & 1.343 & & \multirow{2}{*}{${ }^{*} P<.05,{ }^{* *} P<.01,{ }^{* * *} P<.001$}
\end{tabular}

Second, with implementing the class, the teachers' efficacy for the overall school education has improved $(\mathrm{p}<.05)$ (Table 4.). From this point of view, teachers' efficacy is an important psychological mechanism to figure out the teachers' improvement in applying new teaching methods such as PBL.

Table 4. Comparison in self-efficacy of teachers

\begin{tabular}{c|c|c|c|c|c|c|c}
\hline \multirow{2}{*}{ Variable } & \multicolumn{2}{|c|}{ Pre-test } & \multicolumn{2}{c|}{ Post-test } & \multicolumn{2}{c|}{ Difference } & \multirow{2}{*}{ t-value } \\
\cline { 2 - 7 } & $\mathrm{M}$ & $\mathrm{SD}$ & $\mathrm{M}$ & $\mathrm{SD}$ & $\mathrm{M}$ & $\mathrm{SD}$ & \\
\hline Teacher efficacy & 3.65 & .405 & 3.79 & .423 & -.139 & .628 & $-2.589^{*}$ \\
\hline
\end{tabular}

${ }^{*} P<.05,{ }^{* *} P<.01,{ }^{* * *} P<.001$

Third, teachers suggested a good class is that students can do self-directed learning, feel enjoyment, and be interest in the class. In addition, they mentioned PBL is full of energy, not boring, and students are able to lead the class, understand learning contents, and focus on the class. In addition, teachers reported that PBL is a class where students' cooperation, various outcomes, participation and communication are occurred and thinking ability is enhanced

Fourth, teachers experienced PBL have acquired the knowledge (property of PBL/property of students), behavior (confidence of PBL class), and techniques (designing PBL class, PBL tutoring) at a Level 1 (PBL implementation). In addition, they have figured out the necessary of extension of PBL (school organization, teacher community; researching) at a level 2 (PBL extension). Teacher change and growth has a unique character that includes not only the implementation of PBL at the individual teacher level but also the recognition of the need to expand the PBL to other teachers and schools. Two third of all teachers' answer were about implementing PBL, one third of overall were about PBL extension in school and other teachers. These results suggests that in order to expand PBL classes, it is important not to stay in training and education for teachers but to increase the number of teachers who actually have experience in designing and implementing PBL classes.

\section{CONCLUSION}

According to results of this study, PBL is helpful to make change and growth to both students and teachers. Considering the educational situation in South Korea where in instructor-led class is a lot, the strategies of PBL implement are needed as follows.

First, the specific outcomes and feedbacks of PBL must be shared to students and school parents. Students and school parents would feel hard to be sure about the effects of PBL because the education in South Korea is competitive and focused on students' grade. Therefore, beyond just explaining the PBL and why it is necessary to the students and school parents, it is necessary for school parents and students to bring out the empathy of PBL necessity and participation in PBL by sharing the change and growth of students and teachers have been made. 
Second, the training for implementing PBL are required to the teachers according to the degree of PBL experience. In details, the PBL training need to be separated into three courses; beginner's course, intermediate course, and advanced course. In the beginner course, it is necessary to provide workshops on the main characteristics of the PBL, the development of the problem, and the role of the teacher. In the intermediate course, it needs to be provided a workshop on reflection and consulting after PBL operation. Advanced courses require the PBL case sharing and workshops to improve the competences of PBL instructional consultant. Even if teachers work in the same school, it is desirable to conduct training by experience because PBL implement experience is different.

Third, efforts should be made to secure excellent teachers in PBL field. For this purpose, collaboration between the pre-service teacher training institutes and the offices of education should be the premise. Furthermore, the training content and method should be improved so that the new teacher training program does not simply introduce PBLs and that new teachers have full experience of PBLs.

\section{REFERENCES}

Anderson, L. W. (1976). An empirical investigation of individual differences in time to learn. Journal of educational psychology, 68(2), 226.

Barron, B. J. S., Schwartz, D. L., Vye, N. J., Moore, A., Petrosino, A., Zech, L., Bransford, J.D. \& The Cognition and Technology Group at Vanderbilt (1998). Doing with understanding: lessons from research on problem- and project-based learning. The Journal of the Learning Sciences, 7(3), pp. 271-311.

Barrows, H. S. (1996). Problem-based learning in medicine and beyond: A brief overview. New directions for teaching and learning, 68, 3-12.

Barrows, H. S., \& Myers, A. C. (1993). Problem-Based Learning in Secondary Schools. Unpublished monograph. Springfield, IL: Problem-Based Learning Institute, Lanphier High School and Southern Illinois University Medical School.

Belland, B. R., Ertmer, P. A., \& Simons, K. D. (2006). Perceptions of the value of problem-based learning among students with special needs and their teachers. The Interdisciplinary Journal of Problem-based Learning, 1(2), 1-18.

Blumenfeld, P. C., Soloway, E., Marx, R. W., Krajcik, J. S., Guzdial, M., \& Palincsar, A. (1991). Motivating project-based learning: Sustaining the doing, supporting the learning. Educational psychologist, 26(3-4), 369-398.

Brush, T. \& Saye, J. (2008). The effects of multimedia-supported problem-based inquiry on student engagement, empathy, and assumptions about history. The Interdisciplinary Journal of Problem-based Learning, 2(2), 21-56.

Dunlap, J. C. (2005). Problem-based learning and self-efficacy: How a capstone course prepares students for a profession. Educational Technology Research and Development, 53(1), 65-85.

Finkelstein, N., Hanson, T., Kevin (Chun-Wei) Huang, Klarin, B., \& Huang, M. (2010). Effects of Problem-Based economics on high school economics instruction. US Department of Education.

Geier, R., Blumenfeld, P. C., Mark, R. W., Krajcik, J. S., Fishman, B., Soloway, E. \& Clay-Chambers, J. (2008). Standardized test outcomes for students engaged in inquiry-based science curricula in the context of urban reform. Journal of Research Science Teaching, 45(8), 922-939.

Goddard, R. D., Hoy, W. K., \& Hoy, A. W. (2000). Collective teacher efficacy: Its meaning, measure, and impact on student achievement. American Educational Research Journal, 37(2), 479-507.

Goodnough, K., \& Hung, W. (2009). Enhancing pedagogical content knowledge in elementary science. Teaching Education, 20(3), 229-242.

Grant, M. M. (2011). Learning, beliefs, and products: students' perspectives with project-based learning. The Interdisciplinary Journal of Problem-based Learning, 5(2), pp. 37-69.

Kim, A., \& Kim, M. (2004). Validation of Teacher-Efficacy Scale, The Korean Journal of Educational Psychology, 18(1), p.37-58.

Kim, A., Park, I. (2001). Construction and Validation of Academic Self-Efficacy Scale, The (Korean) Journal of Educational Research, 39(1), 95-123.

Krajcik, J. S., Blumenfeld, P. C., Marx, R. W., \& Soloway, E. (1994). A collaborative model for helping middle-grade science teachers learn project-based instruction. The Elementary School Journal, 94, 483-497.

Markham, T., Larmer, J., \& Ravitz, J. (2003). Project-based learning handbook: a guide to standards-focused Project-Based learning for middle and high school teacher (2nd ed.). CA: Buck Institute for Education.

Mergendoller, J. R., Markham, T., Ravitz, J. \& Larmer, J. (2006). Pervasive management of project-based learning: teachers as guides and facilitators in Evertson, C. M. \& Weinstein, C.S. (Eds), Handbook of Classroom Management: Research, Practice, and Contemporary Issues (pp. 583-615). Mahwah, NJ: Lawrence Erlbaum Associates.

Tawfik, A. A., Trueman, R. J., \& Lorz, M. M. (2013). Designing a PBL environment using the 3C3R method. International Journal of Designs for Learning, 4(1).11-24.

Walker, A., \& Leary, H. (2009). A Problem-Based learning meta analysis: differences across problem types, implementation types, disciplines, and assessment levels. The Interdisciplinary Journal of Problem-based Learning, 3(1), pp. 12-43. 